Visiting UK Paediatricians and Nurses led by Drs Neela Shabde \& Chris Hobbs.

A total of 35 doctors and nurses attended. Eleven candidates were identified as trainers. The 3rd and 4th day was jointly conducted by UK and Nepalese faculty.

Similar courses were held in 2017, 2018 and 2019 with stake holder's involvement of Nepal Paediatric Society, Swantrata Abhiyan Nepal, and some participation of Ministry of Health,Child Workersin Nepal ( CWIN), UNICEF \& Police.

Conclusions

- More than 100 doctors and nurses have been trained including a dedicated pool of trainers to take this forward.

- Two Paediatricians from Nepal have received training at AlderHey Children's Hospital.

- So The Child May Live, UK and Health Exchange Nepal, UK have agreed to fund this project for further 3 years.

- There is a need for a coordination and joining up of services to develop pathways a for referral and management, involving

Department of Social services and the health teams in hospitals. The multiagency response to the child protection training is a priority for developing child protection services in Nepal.

- Support from the UK team should be available during the training courses

\section{G503(P) AN AUDIT OF LENGTH OF TIME TAKEN BEFORE MEDICAL ASSESSMENT OF REFERRALS TO OUR CHILD PROTECTION SERVICE}

${ }^{1}$ OG Forbes, ${ }^{2}$ MK Guilbert. ${ }^{1}$ Child Protection Senvice, Royal Hospital for Children, Glasgow, UK; ${ }^{2}$ School of Medical, Dentistry and Nursing, University of Glasgow, Glasgow, UK

\subsection{6/archdischild-2020-rcpch.428}

Aim To audit whether children were assessed within the time frame as recommended by the $\mathrm{RCPCH}$ (within 24 hours) when referred to our Child Protection Service based at a tertiary paediatric hospital. And to see how many of these children had an Initial Referral Discussion (early formal sharing of information between health, police and social work) prior to examination.

Method This was a retrospective case note review of the cases seen by the Child Protection Service in 2018 for suspected physical abuse. Data was collected from electronic and paper case notes. Children referred for Child Sexual Abuse examinations and comprehensive medical assessments (neglect models) were excluded. In total, we identified 138 cases of children who were referred for medical examination due to a concern of physical abuse.

Results Social Work were the source of referral for $77 / 138$ (56\%) with 38/138 (28\%) from hospital clinicians, 13/138 from GPs (9\%) and 8/138 from police (6\%). 61/138 could be seen to have been examined within 24 hours. The mean time to assessment after referral was 15 hours. The longest time a child had to wait for assessment was 5 days. 54 cases had an IRD before the examination, 42 had an IRD after examination and 42 had no IRD recorded in the notes. Under $1 \mathrm{~s}$ were seen in a much lower mean time of 9 hours.

Conclusion In our busy child protection service based at a tertiary paediatric hospital the mean time to medical assessment after referral was 15 hours. The majority of children were seen within 24 hours (the recommended time from the $\mathrm{RCPCH}$ ). Within the Child protection service child protection consultants have recently moved to a working pattern which includes attendance during evenings and weekends to assess children out of hours and this has had a positive effect on how quickly children are seen. It is noted that many children did not have an IRD as part of this process and further analysis of this is required as to why the other agencies involved in the examination process were not involved within the assessment outcomes.

\section{Paediatric clinical leaders: service planning, provision and best practice}

\section{G504 STRATEGIES EMPLOYED TO ENHANCE RECRUITMENT AND RETENION IN PAEDIATRICS: A SCOPING REVIEW}

${ }^{1} \mathrm{P}$ Mallett, ${ }^{1} \mathrm{~A}$ Thompson, ${ }^{1,2} \mathrm{~T}$ Bourke. 'Dept of Paediatric Simulation and Education, Royal Belfast Hospital for Sick Children, Belfast, UK; ${ }^{2}$ Centre of Medical Education, Queens University of Belfast, Belfast, UK

\subsection{6/archdischild-2020-rcpch.429}

Background In the UK, the proportion of places available in medical school, the total number of foundation doctors, and the number of trainees applying to Paediatrics are falling. The NHS is at 'breaking point', exacerbated by workforce shortages, chronic underfunding, increasing service demand and poor job satisfaction within healthcare workers. Paediatrics in is in the midst of this crisis. Issues in recruitment and retention of paediatricians 'threaten the safety of our children's health' according to the Royal College of Paediatrics and Child Health. In 2019, the RCPCH Executive Committee has prioritised a new recruitment and retention campaign as their key strategic priority for the next three years.

Aim The aim of this study is to explore what strategies have been described in the literature that have been used to enhance recruitment and retention in Paediatrics. This is the first-known scoping review of the literature exploring specific strategies used globally to enhance recruitment and retention in Paediatrics.

Methods A scoping review methodology was conducted, employing a qualitative approach to review the literature on strategies used to improve recruitment and retention in Paediatrics. The studies included were English-language studies. 38 full-text articles were reviewed and analysed by the research team.

Study Findings Despite the importance of this issue, there is a paucity of data in the literature that describes evidence-based approaches to improving retention and recruitment in Paediatrics. The most important strategies employed to help are identified and collated using validated PRISMA criteria for systematic reviews. The findings were grouped into six main themes of professional advocacy, workforce diversity, mentorship, improving working conditions, career flexibility and enhancing educational opportunities. The authors propose a strategic modified 'Paediatric Pipeline' paradigm of 'Identify, Engage, Recruit, Retain and Champion.'

Conclusions There appear to be three main elements that are key to recruitment and retention of Paediatricians: personal, professional and systemic factors. Whilst some of the issues encountered share similarities with other medical specialities in difficulty, much of the context and potential remedies within Paediatrics are distinct. A strategic, multi-agency international collaborative approach is required urgently to address the significant issues that face both Paediatrics and the healthcare system itself. 